\title{
Effects of ram sperm acrosin on the investments of sheep, pig, mouse and gerbil eggs
}

\author{
C. R. Brown \\ A.R.C. Institute of Animal Physiology, Animal Research Station, 307 Huntingdon Road, \\ Cambridge CB3 OJQ, U.K.
}

\begin{abstract}
Summary. The effects of various concentrations of highly purified preparations of ram sperm acrosin were tested in a balanced medium on the cumulus oophorus, corona radiata and zona pellucida of sheep, pig, mouse and gerbil eggs. The enzyme had a variety of effects depending upon the species of egg. These effects ranged from complete removal of all the investments from the mouse egg to a failure to remove any of the investments from the sheep egg. The in-vitro autoactivation of ram sperm proacrosin to acrosin was unmodified in the presence of various fluids from the sheep reproductive tract. It is concluded that any role for soluble ram acrosin in sperm penetration of the sheep zona pellucida is likely to be of a synergistic nature.
\end{abstract}

\section{Introduction}

Two criteria have been used to support the contention that the acrosomal proteinase acrosin (EC 3.4.21.10) is essential for the passage of the spermatozoon through the zona pellucida of the egg during fertilization. First, it has been shown that purified acrosin and acrosin-rich acrosomal extracts from spermatozoa will digest and remove the zona pellucida from the egg of several species (Srivastava, Adams \& Hartree, 1965; Stambaugh \& Buckley, 1969; Polakoski \& McRorie, 1973; Meizel \& Mukerji, 1976). Second, it has been observed that digestion of the zona pellucida and fertilization can be impaired by the application of acrosin inhibitors to test systems (Stambaugh \& Buckley, 1969; Stambaugh, Brackett \& Mastroianni, 1969; Zaneveld, Robertson, Kessler \& Williams, 1971; Yang, Zaneveld \& Schumacher, 1976; Meizel \& Mukerji, 1976). Hitherto, most studies on the effect of acrosin on eggs have involved rodents or rabbits, often with acrosin from an unrelated species. Observations on the effect of a pure, well defined acrosin on homologous eggs are lacking, especially so in the case of large domesticated species. Acrosin is derived from an intra-acrosomal inactive precursor, proacrosin (Meizel \& Mukerji, 1975). A relatively stable enzyme of molecular weight $\sim 44000$, designated $\beta$-acrosin, and a less stable group of enzymes of lower molecular weight, designated as $\psi$-acrosin, are generated when ram proacrosin is activated in vitro (Brown \& Harrison, 1978; Brown \& Hartree, 1978). However, little is yet known about the activation of proacrosin within the female reproductive tract. In this communication the effects of sheep reproductive tract fluids on the activation of ram sperm proacrosin are investigated, and the ability of highly purified $\beta$-acrosin and of $\psi$-acrosin to disperse the zona pellucida, corona radiata and cumulus oophorus of sheep eggs is compared with their effects on the corresponding investments of mouse, gerbil and pig eggs. 


\section{Materials and Methods}

\section{Medium for acrosin-egg incubations}

The balanced medium, $\mathrm{pH} 7.2$, was that described by Trounson, Willadsen \& Rowson (1976) except that bovine serum albumin $(4 \mathrm{mg} / \mathrm{ml})$ was used in place of fetal calf serum. Kanamycin sulphate $(0.05 \mathrm{mg} / \mathrm{ml})$ was included.

\section{Preparation of acrosins}

Pure $\beta$-acrosin, with a specific activity towards $N \alpha$-benzoyl-L-arginine ethyl ester (BAEE: Sigma (London) Chemicals Ltd, Poole, Dorset, U.K.) of 140 units/mg, was prepared from ejaculated ram spermatozoa (Brown \& Hartree, 1978) and assayed by the method of Brown, Andani \& Hartree (1975). $\psi$-Acrosin was eluted from the same affinity column using 0.25 mM-p-aminobenzamidine at $\mathrm{pH} 6$ (Brown \& Hartree, 1978) acidified to $\mathrm{pH} 2.7$ with $\mathrm{HCl}$, dialysed against $1 \mathrm{~mm}-\mathrm{HCl}$ followed by distilled water and freeze-dried to give a product with a specific activity of $80 \mathrm{i} . \mathrm{u} . / \mathrm{mg}$ towards BAEE. Immediately before use the enzyme was dissolved in medium in which the catalytic activities of $\beta$ - and $\psi$-acrosins towards BAEE were reduced by $70 \%$.

\section{Collection of eggs}

Sheep eggs were collected from non-atretic follicles and matured in vitro for $24 \mathrm{~h}$ (Moor \& Trounson, 1977). Pig eggs were taken from mature follicles of animals slaughtered not more than $1 \mathrm{~h}$ previously and used immediately. Mouse eggs were collected from the oviducts of 26-28-day-old-CFLP females treated previously with 12 i.u. PMSG (48 h) and 12 i.u. hCG (18 h) and used immediately or after a 24-h culture (Moor \& Trounson, 1977). Eggs from the Mongolian gerbil were flushed with 'medium' from the oviducts of animals $24 \mathrm{~h}$ post partum. For each species eggs were left in a cumulus oophorus and corona radiata or in a corona radiata. For some experiments both these investments were removed non-enzymically by gentle suction into and out of a fine-bored Pasteur pipette.

\section{Incubation of eggs with acrosin preparations}

All incubations were carried out in plastic microtest plates with wells $15 \mathrm{~mm}$ in diameter and $10 \mathrm{~mm}$ deep. They were at $37^{\circ} \mathrm{C}$ in a final volume of $0.05 \mathrm{ml}$ medium and covered with liquid paraffin. Transfer of eggs was carried out with a siliconized pipette attached to a microburette; this enabled transfer volumes to be recorded and the final volume of incubations to be accurately standardized. Manipulation of eggs was carried out under a Wild M7 stereomicroscope while more critical examinations were made with a Vickers Patholux microscope with $\times 50$ magnification. Each incubation contained no less than 15 eggs (mouse) or 6 eggs (gerbil, sheep or pig) and final concentrations of acrosin ranging from 0 to $20 \mathrm{mg} / \mathrm{ml}$. The inherent instability of $\psi$-acrosin (activity towards BAEE fell by $60 \%$ in $3 \mathrm{~h}$ at $37^{\circ} \mathrm{C}$ ) required that for 7 -h incubations with this enzyme eggs had to be transferred to a second and third solution of freshly dissolved enzyme. In all experiments controls were run in which eggs were incubated in 'medium' alone.

\section{Collection of material from the reproductive tract of the sheep}

Follicular fluid was withdrawn from preovulatory follicles of two sheep in oestrus and one in the luteal phase and contained between 85 and $100 \mathrm{mg}$ protein $/ \mathrm{ml}$. The oviducts and uteri of 3 sheep slaughtered in oestrus and 3 slaughtered in the luteal phase were each flushed with $0.6 \mathrm{ml}$ 
and $7 \mathrm{ml} 0.154 \mathrm{M}-\mathrm{NaCl}$ respectively. After removal of tissue fragments the oviduct fluid contained $1.5-2.0 \mathrm{mg}$ protein $/ \mathrm{ml}$ whilst that from the uterus contained $0.4-0.7 \mathrm{mg}$ protein $/ \mathrm{ml}$.

Activation of ram proacrosin in the presence of follicular fluid and flushings from the oviduct and uterus of the sheep

The proacrosin activation system employed was that described by Brown \& Harrison (1978) in which ram sperm heads are isolated in the presence of a chemical acrosin inhibitor, $p$-aminobenzamidine, which arrests autoactivation of proacrosin. Subsequent removal of the inhibitor permits autoactivation to proceed, and this is then monitored at intervals by measurement of acrosin activity and by electrophoretic analysis on non-denaturing polyacrylamide gels of the enzyme forms which have been generated. In the present experiments ram sperm heads were incubated at a concentration of $0.5 \times 10^{9} / \mathrm{ml}$ in $0.125 \mathrm{M}$-sucrose, 0.077 M-sodium chloride and $0.01 \mathrm{M}$-Hepes ( $N$-2-hydroxy-ethylpiperazine- $N^{\prime}$-2-ethanesulphonic acid) $\mathrm{pH} 7.5$ at $25^{\circ} \mathrm{C}$. Activation of proacrosin was allowed to proceed in the absence or presence of various concentrations of follicular fluid, oviduct and uterine flushings, maximum final concentrations of these being $45,0.9$ and $0.3 \mathrm{mg}$ protein $/ \mathrm{ml}$ respectively. At various intervals aliquots of each incubation system were removed, assayed for acrosin activity and examined electrophoretically for the various molecular forms of the enzyme generated as detailed by Brown \& Harrison (1978).

\section{Measurement of protein}

The Hartree modification (1972) of the Lowry procedure was used with bovine serum albumin as standard. Pronase was supplied by Cambrian Chemicals Ltd, London, U.K.

\section{Results}

Influence of follicular, oviducal and uterine fluids on ram proacrosin activation

These fluids did not influence the autoactivation of ram sperm proacrosin, irrespective of the stage of the oestrous cycle. The rate of activation to $\beta$-acrosin and the enzyme forms produced were similar to those reported by Brown \& Harrison (1978).

\section{Effects of ram sperm acrosin on egg investments (Table 1)}

Mouse. Both $\beta$ - and $\psi$-preparations of acrosin at concentrations of $0.05 \mathrm{mg} / \mathrm{ml}$ completely dispersed the cumulus oophorus and corona radiata within $15 \mathrm{~min}$, leaving a cell-free outer surface of the zona pellucida. Eggs with investments removed in this way were then washed thoroughly in 'medium' and used to test the effect of various concentrations of $\beta$ - and $\psi$-acrosin on the zona pellucida (Table 1). During dissolution the zonae pellucidae did not become more translucent or swell but erosion began at the outer surface and progressed inwards. These effects were consistent and independent of the preparation and concentration of enzyme used. Eggs incubated in medium alone remained visibly unaffected for $18 \mathrm{~h}$, demonstrating the efficacy of the wash following removal of the cumulus oophorus and corona radiata with the low concentration of $\beta$-acrosin. Similar results were obtained with mouse eggs which had been cultured for $24 \mathrm{~h}$ (Moor \& Trounson, 1977).

Gerbil, pig and sheep. There was no detectable difference between the effects of the two preparations of acrosin on the investments of these eggs, although their effect varied according to species (Table 1). Acrosin failed to remove the zona pellucida from any of the eggs, and failed to remove any of the investments from sheep eggs. At concentrations $>1 \mathrm{mg} / \mathrm{ml}$ the enzyme did, 
Table 1. Summary of the effects of ram sperm acrosin on the time (h) taken for complete removal of the investments of mouse, gerbil, pig and sheep eggs

\begin{tabular}{|c|c|c|c|c|c|c|}
\hline & \multicolumn{6}{|c|}{ Acrosin ${ }^{*}$ conc. $(\mathrm{mg} / \mathrm{ml})$} \\
\hline & 0.05 & $0 \cdot 1$ & 0.5 & 5 & 10 & 20 \\
\hline \multicolumn{7}{|l|}{ Mouse } \\
\hline Cumulus oophorus + corona radiata & 0.25 & $<0.1$ & $<0.05$ & $<0.05$ & n.t. & n.t. \\
\hline Zona pellucida & $>18$ & 18 & 4.5 & 1 & 0.3 & n.t. \\
\hline \multicolumn{7}{|l|}{ Gerbil } \\
\hline Cumulus oophorus + cornona radiata & $<0.1$ & $<0.05$ & $<0.05$ & $<0.05$ & n.t. & n.t. \\
\hline Zona pellucida & r. & r. & r. & r. & r. & r. \\
\hline \multicolumn{7}{|l|}{ Pig } \\
\hline Cumulus oophorus & n.t. & n.t. & n.t. & 0.25 & 0.1 & n.t. \\
\hline Corona radiata & n.t. & n.t. & n.t. & p.r. & p.r. & n.t. \\
\hline Zona pellucida & r. & r. & r. & r. & r. & r. \\
\hline \multicolumn{7}{|l|}{ Sheep } \\
\hline Cumulus oophorus & r. & r. & r. & r. & r. & r. \\
\hline Corona radiata & r. & r. & r. & r. & r. & r. \\
\hline Zona pellucida & r. & r. & r. & r. & r. & r. \\
\hline
\end{tabular}

* Both preparations of acrosin were tested for periods up to $7 \mathrm{~h}$, but only $\beta$-acrosin was tested beyond $7 \mathrm{~h}$. n.t. $=$ not tested; r. $=$ retained; p.r. $=$ partly retained.

Values shown as r. or p.r. were tested for $20 \mathrm{~h}$.

within $2 \mathrm{~h}$, have a mild but visibly detectable effect on the sheep zona pellucida; the outer surface became less well defined, appearing irregular and giving the impression that some degree of erosion may have occurred. However, this did not increase even following prolonged incubation at enzyme concentrations of $20 \mathrm{mg} / \mathrm{ml}$. An effect seen only with pig eggs was the complete removal of the cumulus oophorus and only partial removal of the corona radiata; a layer of corona cells persisted throughout prolonged incubation at enzyme concentrations of 5 and 10 $\mathrm{mg} / \mathrm{ml}$. Eggs incubated in medium alone were visibly unaffected over $24 \mathrm{~h}$.

\section{Digestion of zonae pellucidae with pronase}

In all the above experiments in which the zonae pellucidae proved resistant to acrosin, the eggs were subsequently subjected to pronase digestion at $5 \mathrm{mg} / \mathrm{ml}$ in medium; the zonae were always completely removed within $15 \mathrm{~min}$.

\section{Discussion}

The results described above demonstrate that a variety of effects may be observed when eggs from several different species are incubated in a balanced medium with purified preparations of ram sperm acrosin. The most comprehensive effect was seen with mouse eggs from which the cumulus oophorus, corona radiata and zona pellucida were rapidly removed. In complete contrast to this, all the investments surrounding cultured sheep eggs were retained, even in high concentrations of acrosin. Sheep eggs matured in this way are subsequently capable of becoming fertilized in vivo (Moor \& Trounson, 1977) and are therefore a legitimate test system. Moreover, the same culture conditions imposed on mouse eggs did not alter the overall susceptibility of their investments to dissolution by acrosin. A difference was also seen in response between the two species of rodent, the gerbil zona pellucida persisting in high concentrations of acrosin. For pig eggs only the cumulus oophorus and the outer cells of the corona radiata were removed, thus providing another variation in response to ram sperm acrosin. 
Although a range of concentrations of acrosin has been used in this investigation the upper limit of $20 \mathrm{mg} / \mathrm{ml} \mathrm{might} \mathrm{appear} \mathrm{rather} \mathrm{high.} \mathrm{However,} \mathrm{the} \mathrm{use} \mathrm{of} \mathrm{this} \mathrm{concentration} \mathrm{of} \mathrm{enzyme}$ may be justified on the grounds that the concentration of (pro)acrosin within the intact ram sperm acrosome is approximately $2 \mathrm{mM}$, i.e. $\gg 40 \mathrm{mg} / \mathrm{ml}$ (Brown \& Hartree, 1976). Therefore it is possible that after the acrosome reaction quite high concentrations of acrosin could occur locally. It has been shown in the guinea-pig that activation of proacrosin accompanies an ionophore-induced acrosome reaction (Green, 1978) and in the ram that mechanical disruption of the acrosome will initiate the activation process (Brown \& Harrison, 1978). Should the same relationship between a physiological acrosome reaction and proacrosin activation exist, and should the acrosome reaction in vivo occur with the sperm head proximal to the surface of the zona pellucida, then this investment could be subjected to a very localized high concentration of acrosin or its activating precursor(s). On the other hand, it has been reported that proacrosin activation occurs when boar spermatozoa are placed in the uterus of the sow (Polakoski, Clegg \& Parrish, 1979), although in these experiments spermatozoa were first exposed to oviduct fluid and an effect of this cannot be ruled out. Activation of proacrosin while spermatozoa are in the uterus would be biologically premature, particularly if activation were accompanied by the acrosome reaction.

The effect of ram sperm acrosin on the egg investments of other species, and its apparent negative effect on sheep egg investments, further obscures the role of this enzyme in fertilization. However, the present results strongly suggest that the action of acrosin alone would not suffice to facilitate sperm passage through sheep egg investments, unless it is able to do so as a membrane-bound enzyme (Brown \& Hartree, 1976), because it is ineffective or even contraceptive in the soluble form. Exposure of hamster eggs to a low concentration of soluble homologous acrosin may prevent fertilization, apparently by destroying sperm binding sites (Gwatkin, Wudl, Hartree \& Fink, 1977). In the sheep also an anti-fertility effect may be induced with $\beta$-acrosin (R. M. Moor, C. R. Brown \& E. F. Hartree, unpublished experiments), whereby spermatozoa will become embedded in the outer surface of the zona pellucida of ovulated eggs but cannot pass through it. The outer surface of the sheep zona pellucida treated in this way becomes irregular and loses definition, indicative of a limited degree of proteolysis because in the present experiments very much higher concentrations of $\beta$ - and $\psi$-acrosin failed to extend this visible effect beyond the surface of the investment. It has been suggested that any possible antifertility effect of soluble acrosin may be counteracted by the action of a protease inhibitor endogenous to the ram sperm acrosome, and strongly inhibitory towards soluble acrosin (Brown \& Hartree, 1976). This would seem to be a reasonable suggestion, but if acrosin is involved in penetration of the sheep zona pellucida then the same hypothesis would also necessitate an inhibitor-resistant form of acrosin, perhaps a membrane-bound form (Brown \& Hartree, 1976; Hartree, 1977).

Alternatively, as a necessary prerequisite to any effective proteolysis of the zona pellucida by acrosin (soluble or bound) a structural alteration of the investment may be required, mediated by enzymic factors originating from the acrosome or by factors in the female reproductive tract. This would amount to a synergism between acrosin and another factor(s) which could include several of the other hydrolytic enzymes thought to be associated with the acrosome (McRorie \& Williams, 1974). Some evidence for this possibility has been found in the rabbit (Srivastava, Akruk \& Williams, 1979).

Further investigation is needed to elucidate the role of acrosin in ovine fertilization, a role which may not be related to penetration of the zona pellucida as indicated by Bedford \& Cross (1978). Indeed, evidence has been obtained indicating a possible role for acrosin in the acrosome reaction (Meizel \& Lui, 1976) or in dispersal of the acrosomal matrix during the course of this reaction (Green, 1978).

I thank Dr R. M. Moor for supplying matured sheep eggs. 


\section{References}

Bedford, J.M. \& Cross, N.L. (1978) Normal penetration of rabbit spermatozoa through a trypsin- and acrosin-resistant zona pellucida. J. Reprod. Fert. 54, 385-392.

Brown, C.R. \& Harrison, R.A.P. (1978) The activation of proacrosin in spermatozoa from ram, bull and boar. Biochem. Biophys. Acta 526, 202-217.

Brown, C.R. \& Hartree, E.F. (1976) Effects of acrosin inhibitors on the soluble and membrane-bound forms of ram acrosin, and a reappraisal of the role of the enzyme in fertilization. Hoppe-Seyler's Z. Physiol. Chem. 357, 57-65.

Brown, C.R. \& Hartree, E.F. (1978) Studies on ram acrosin. Activation of proacrosin accompanying the isolation of acrosin from spermatozoa, and purification of the enzyme by affinity chromatography. Biochem. J. 175, 227-238.

Brown, C.R., Andani, Z. \& Hartree, E.F. (1975) Studies on ram acrosin. Isolation from spermatozoa, activation by cations and organic solvents, and influence of cations on its reaction with inhibitors. Biochem. J. 149, 133-146.

Green, D.P.L. (1978) The activation of proteolysis in the acrosome reaction of guinea-pig sperm. J. Cell Sci. 32, 153-164.

Gwatkin, R.B.L., Wudl, L., Hartree, E.F. \& Fink, E. (1977) Prevention of fertilization by exposure of hamster eggs to soluble acrosin. J. Reprod. Fert. 50, 359-361.

Hartree, E.F. (1972) Determination of protein: a modification of the Lowry method that gives a linear photometric response. Analyt. Biochem. 48, 422-427.

Hartree, E.F. (1977) Spermatozoa, eggs and proteinases. Biochem. Soc. Trans. 5, 375-394.

McRorie, R.A. \& Williams, W.L. (1974) Biochemistry of mammalian fertilization. A. Rev. Biochem. 43, $777-803$.

Meizel, S. \& Lui, C.W. (1976) Evidence for the role of a trypsin-like enzyme in the hamster sperm acrosome reaction. J. exp. Zool. 195, 137-144.

Meizel, S. \& Mukerji, S.K. (1975) Proacrosin from rabbit epididymal spermatozoa: partial purification and initial characterization. Biol. Reprod. 13, 83-93.
Meizel, S. \& Mukerji, S.K. (1976) Biochemical studies of proacrosin and acrosin from hamster cauda epididymal spermatozoa. Biol. Reprod. 14, 444-450.

Moor, R.M. \& Trounson, A.O. (1977) Hormonal and follicular factors affecting maturation of sheep oocytes in vitro and their subsequent developmental capacity. J. Reprod. Fert. 49, 101-109.

Polaskoski, K.L. \& McRorie, R.A. (1973) Boar acrosin. II. Classification, inhibition, and specificity studies of a proteinase from sperm acrosomes. J. biol. Chem. 248, 8183-8188.

Polakoski, K.L., Clegg, E.D. \& Parrish, R.F. (1979) Identification of the in vivo sperm proacrosin into acrosin conversion sequence. Int. J. Biochem. 10, 483-488.

Srivastava, P.N., Adams, C.E. \& Hartree, E.F. (1965) Enzymic actions of acrosomal preparations on the rabbit ovum in vitro. J. Reprod. Fert. 10, 61-67.

Srivastava, P.N., Akruk, S.R. \& Williams, W.L. (1979) Dissolution of rabbit zona by sperm acrosomal extracts: effect of calcium (1). J. exp. Zool. 207, 512-529.

Stambaugh, R. \& Buckley, J. (1969) Identification and subcellular localization of the enzymes affecting penetration of the zona pellucida by rabbit spermatozoa. J. Reprod. Fert. 19, 423-432.

Stambaugh, R., Brackett, B.C. \& Mastroianni, L. (1969) Inhibition of in vitro fertilization of rabbit ova by trypsin inhibitors. Biol. Reprod. 1, 223-227.

Trounson, A.O., Willadsen, S.M. \& Rowson, L.E.A. (1976) The influence of in vitro culture and cooling on the survival and development of cow embryos. $J$. Reprod. Fert. 47, 367-370.

Yang, S.L., Zaneveld, L.J.D. \& Schumacher, G.F.B. (1976) Effect of serum proteinase inhibitors on the fertilizing capacity of rabbit spermatozoa. Fert. Steril. 27, 577-588.

Zaneveld, LJ.D., Robertson, R.T., Kessler, M. \& Williams, W.L. (1971) Inhibition of fertilization in vivo by pancreatic and seminal plasma trypsin inhibitors. J. Reprod. Fert. 25, 387-392.

Received 1 June 1981 